\title{
As práticas contábeis relativas à mensuração e evidenciação dos estoques em empresas industriais do mercosul e comunidade andina estão convergentes com a norma do IASB?
}

\section{Accounting practices related to measurement and disclosure of stock in mercosul and andean community industrial companies: are they in tune with IASB guidelines?}

¿Las prácticas contables relativas a la medición y a la publicación de los inventarios en las empresas industriales del mercosur y de la comunidad andina están convergiendo con la norma de IASB?

João Luis Peruchena Thomaz

Mestre em Ciências Contábeis pela Universidade do Vale dos Sinos/UNISINOS

Professor do Curso de Ciências Contábeis - URCAMP/Bagé

Endereço: Rua Rivadávia Correa $\mathrm{n}^{\circ} 1158$ Apto. 102 - Centro

CEP: 97.573-010 - Santana do Livramento/RS - Brasil

E-mail: prof.peruchena@gmail.com

Telefone: (55) 9956-9336

\section{Clóvis Antônio Kronbauer}

Doutor em Contabilidade e Auditoria - Universidade de Sevilha - Espanha

Professor do PPG em Ciências Contábeis - Unisinos/RS

Av. Pedro Américo no 34 apto. 301 - São José

CEP: 93.040-120 - São Leopoldo/ RS - Brasil

E-mail: clovisk@unisinos.br

Telefone: (51) 9997-0995

\section{Bianca Bigolin Liszbinski}

Mestre em Ciências Contábeis - UNISINOS

Rua Thomaz Albornoz, 285 - Centro

CEP: 97.573-010 -- Santana do Livramento/RS - Brasil

Email: biancabliszbinski@hotmail.com

Telefone: (55) 9159-3556

Artigo recebido em 07/05/2013. Revisado por pares em 06/08/2013. Reformulado em 13/09/2013. Recomendado para publicação em 26/10/2013 por Sandra Rolim Ensslin (Editora Científica). Publicado em 15/12/2013. 


\title{
Resumo
}

O estudo objetivou analisar a convergência das práticas contábeis no tratamento dos estoques no Mercosul e na Comunidade Andina. Analisou-se uma amostra de trinta empresas industriais, selecionadas por intencionalidade e acessibilidade. Os dados obtidos nos sítios das comissões de mercados de valores em cada país foram sumarizados em quadros descrevendose a mensuração e evidenciação dos estoques. Constataram-se práticas ainda muito heterogêneas, pois em alguns países a convergência é quase total à IAS 2 e, em outros, isso parece distante. Observou-se ainda, que a adoção da norma internacional relacionada aos estoques não significa a convergência na prática, havendo ainda um caminho a percorrer para que as práticas contábeis relativas aos estoques estejam completamente harmonizadas nas regiões estudadas.

Palavras-chave: Estoques. Mensuração e evidenciação. Convergência contábil.

\begin{abstract}
This study sought to analyze the convergence in accounting practices as regards the treatment of stock in MERCOSUL and in Andean Community. A sample that included 30 industrial companies was investigated. These companies were selected according to their accessibility and intentionality. Data obtained in the sites of market commission in each country were summarized in tables describing measurement and disclosure of stock. It was observed that practices are still much heterogenic, for in some countries convergence is almost equal to IAS 2 and, in other countries that still seems to be distant. It was also observed that the adoption of the international guidelines related to stock does not indicate convergence in the practice of these companies, showing that there is still much to be done so that accounting practices related to stock are in complete harmony with the studied regions.
\end{abstract}

Keywords: Stock. Measurement and disclosure. Convergence of accounting standards.

\section{Resumen}

El estudio tuvo como objetivo analizar la convergencia de las prácticas contables en el tratamiento de los inventarios en el MERCOSUR y en la Comunidad Andina. Se analizó una muestra de treinta empresas industriales, seleccionadas por intencionalidad y accesibilidad. Los datos obtenidos en los sitios web de las comisiones de mercados de valores de cada país se resumen en las tablas que describen la medición y la publicación de los inventarios. Se constató una práctica muy heterogénea, ya que en algunos países la convergencia es casi total a la IAS 2 y en otros esto parece distante. También se observó que la adopción de la norma internacional relacionada con los inventarios no significa convergencia en la práctica, todavía hay un largo camino por recorrer, para que las prácticas contables relativas a los inventarios estén plenamente armonizadas en las regiones estudiadas.

Palabras clave: Inventarios. Medición y divulgación. Convergencia de Contabilidad. 
1 Introdução

O processo de integração econômica na América Latina teve sua origem por volta de 1750 e vários foram os mecanismos constituídos buscando consolidar essa integração. Como exemplos, pode-se citar a "Pátria Grande" (KUNZLER, 2001); o "Tratado del ABC" (1915) entre Argentina, Brasil e Chile, cujo objetivo era o equilíbrio no Cone Sul do hemisfério americano; a Comissão Econômica para América Latina (1948), com a finalidade de estimular a criação de um mercado comum; a Associação Latino-Americana de Livre Comércio (1960) envolvendo Brasil, Argentina, Chile, México, Uruguai, Paraguai e Peru (SOSA, 2008); a Associação Latino-Americana de Integração (1980), com o objetivo de criar tarifas e acordos regionais entre dois ou mais países (FLORÊNCIO; ARAÚJO, 1998).

Em 1990, Brasil e Argentina formaram um Mercado Comum, com posterior adesão do Uruguai e do Paraguai. Essa união proporcionou um novo impulso ao processo de integração que culminou na constituição do Mercosul, bloco econômico classificado como de terceiro nível de colaboração econômica, que se caracteriza pelo livre comércio, a união aduaneira e mais a livre circulação de pessoas, serviços, bens e capitais (BASSO, 1995). Atualmente, além de Argentina, Brasil, Paraguai e Uruguai, que são membros fundadores do bloco, houve o ingresso da Venezuela em 2006. Em 2012, devido à crise política que passa o Paraguai e tendo em vista que o Mercosul prima pelos compromissos democráticos, este país foi suspenso do bloco até que seja reestabelecida a ordem democrática naquela república (MERCOSUR, 2012).

Por sua vez, o bloco econômico da Comunidade Andina não avançou tanto quanto o Mercosul, ficando no segundo nível de colaboração econômica, que é caracterizado pela união aduaneira que implica o livre comércio e o estabelecimento de uma tarifa externa comum (BASSO, 1995). O histórico de constituição desse bloco teve início em 1960 com o Acordo Sub-Regional Andino entre Colômbia, Chile, Venezuela e Bolívia. (SOSA; FERRETTI, 2007). Logo após, em 1969, com o Acordo de Cartagena entre Bolívia, Chile, Equador e Peru, criou-se o Pacto Andino. Já em 1966 estes mesmos países assinaram o Protocolo de Trujillo, criando o bloco econômico denominado Comunidade Andina.

Diante desse cenário de integração econômica é necessário que o processo de geração de informações financeiras esteja integrado, embora características individuais de cada país possam permanecer e esse é um fator que traz implicações importantes às normas e práticas contábeis nos países desses dois blocos econômicos. No Mercosul e na Comunidade Andina, essa integração ainda não ocorreu. Para a contabilidade, esse processo de harmonização é um desafio marcado pela busca de um conjunto mínimo de normas contábeis que devem ser adotadas pelos países-membros da união econômica e monetária (KRONBAUER, 2006).

Especificamente, a harmonização de práticas contábeis está relacionada aos critérios de avaliação patrimonial, até porque diferentes critérios causam diferença no valor das empresas e acabam interferindo no valor dos resultados apurados. Assim, a adoção de um conjunto harmônico de normas contábeis poderia diminuir a assimetria de informações divulgadas.

Com a convergência aos padrões de contabilidade internacional, o tratamento contábil dos estoques sofreu mudanças significativas, principalmente com relação a sua mensuração, pelo valor de custo ou pelo valor realizável líquido, e aos critérios de evidenciação. Nesse contexto, o objetivo principal deste estudo é investigar as normas e práticas contábeis adotadas por empresas industriais do Mercosul e da Comunidade Andina relativas a estoques 
e avaliar o nível de convergência no tratamento contábil desses elementos patrimoniais.

Os estoques constituem-se em um ativo relevante para as empresas industriais e disso decorre a necessidade do adequado controle, mensuração e posterior evidenciação nas demonstrações contábeis (IUDÍCIBUS et al., 2010). Classificam-se como estoques aqueles bens adquiridos e destinados para venda, os produtos acabados, os produtos em elaboração, as matérias-primas e os materiais utilizados no processo de produção (SCARIOT, 2011), sendo que são elementos diretamente ligados à contabilidade de custos, devido a sua forma de avaliação (SOUZA; DIEHL, 2009; LEONE; LEONE, 2010).

A escolha deste tema deu-se em função de estudos precedentes terem sido realizados somente no âmbito do Mercosul (POHLMANN, 1995; LISBOA, 2000; AMENÁBAR, 2001). Além disso, a pesquisa possibilita a identificação da atual situação do processo de convergência das normas contábeis relacionada aos estoques nesses blocos econômicos.

\section{Referencial da Literatura}

\subsection{Normas Contábeis Internacionais e o Processo de Convergência no Mercosul e na Comunidade Andina}

A contabilidade, em uma economia globalizada, cumpre o papel de fornecer uma informação financeira adequada para a tomada de decisão e acessível a mercados internacionais (SOSA, 1999). Diante desse contexto, a globalização da economia é considerada o principal propulsor do processo de harmonização contábil, que tem por finalidade atingir um alto grau de comparabilidade da informação financeira no âmbito internacional, facilitando a comunicação e contribuindo para a redução de diferenças internacionais no financial reporting (NIYAMA, 2010).

Adicionalmente, é importante ressaltar a função dos órgãos reguladores dos mercados de capitais de determinados países, especialmente dos Estados Unidos da América, que formularam exigências que fizeram com que o processo de convergência contábil se tornasse realidade (SÁNCHEZ, 2010). A esse respeito, surgiu em 1973 o Comitê de Normas Internacionais de Contabilidade (IASC), mediante um acordo entre os organismos representativos da profissão contábil da Austrália, Canadá, França, Alemanha, Japão, México, Holanda, Reino Unido, Irlanda e dos Estados Unidos da América, representando mais de 143 entidades profissionais, envolvendo mais de 104 países. Esse organismo, reformulado no ano de 2001, passou a ser denominado International Accounting Standards Board (IASB), e tem por responsabilidade a emissão de normas contábeis de aplicação internacional (MACIEL, 2009).

Por ser um organismo privado, os pronunciamentos do ISAB consideram-se como não compulsórios, e carecem de regulamentos legais para se fazerem obrigatórios. Por outro lado, são uma referência técnica que facilita a interpretação das informações contábeis por parte de investidores, autoridades ou agentes econômicos em geral (NIYAMA, 2010).

A convergência aos padrões contábeis internacionais no Mercosul e na Comunidade Andina é diferenciada em cada país que compõe esses blocos econômicos. Na Argentina, a Comissão Nacional de Valores (CNV), a Federação Argentina de Conselhos Profissionais de Ciências Econômicas e o Conselho Profissional de Ciências Econômicas da Cidade Autônoma de Buenos Aires elaboraram, conjuntamente, um plano de implementação das 
normas contábeis emitidas pelo IASB. A Resolução Técnica n. 26 determinou a obrigatoriedade da adoção pelas entidades que realizam oferta pública de capital e que estão sob o controle da CNV. Tais empresas poderiam adotar voluntariamente as normas internacionais a partir de 2011, e de forma obrigatória em 2012.

Na Bolívia, o Colégio de Auditores e Contadores Públicos da Bolívia assinou um convênio de cooperação técnica com o Banco Interamericano de Desenvolvimento, denominado projeto ATN/MT-100078-BO, o qual estabeleceu um plano de convergência das normas bolivianas com as normas internacionais. Em 2011, foram aprovadas e regulamentadas as primeiras dezesseis normas internacionais de contabilidade, incluindo o marco conceitual.

No Brasil, por meio da Resolução CFC n. 1.055/05, criou-se o Comitê de Pronunciamentos Contábeis (CPC) que teve por finalidade viabilizar a convergência das normas contábeis brasileiras aos padrões internacionais. Em 2006, o Banco Central do Brasil publicou o Comunicado n. 14.259, determinando a obrigatoriedade da elaboração das demonstrações contábeis consolidadas com base nas IFRS (Internacional Financial Reporting Standars), a partir de 2010. A Deliberação n. 457, a Comissão de Valores Mobiliários (CVM) obrigou as companhias abertas a publicarem suas demonstrações contábeis consolidadas, integralmente em IFRS, a partir de 2010. Em 2008, com a vigência da Lei n. 11.638/2007, modificada pela Lei n. 11.941/2009, oficializou-se a convergência aos padrões contábeis internacionalmente aceitos. A partir do exercício de 2008, todas as empresas poderiam optar pela elaboração das demonstrações contábeis de acordo com o padrão internacional, e, em 2010, deveriam adotar obrigatoriamente essas instruções.

No Chile, o Conselho Nacional do Colégio de Contadores aprovou em 1997 a harmonização dos princípios e das normas contábeis chilenas às normas internacionais de contabilidade, com adoção de forma optativa entre 2009 e 2010. Em 2008, a Superintendência de Valores e Seguros do Chile estabeleceu a adoção das IFRS para todas as entidades inscritas no registro de valores, com um programa de transição entre 2009 e 2011.

Na Colômbia, em 2009, a Superintendência de Serviços Públicos estabeleceu um período progressivo para a aplicação do modelo geral às normas internacionais de contabilidade, sendo que 2010 foi o ano de transição e, 2011, de convergência às IFRS. Para as demais empresas, estabeleceu-se um plano de adoção que iniciou 2010 e que deveria estar concluso em junho de 2012, mas não havia uma data definida para a aplicação das IFRS.

No Equador, a Superintendência de Companhias adotou as normas internacionais de informação financeira e determinou sua aplicação por parte das companhias e entidades sujeitas ao seu controle e vigilância a partir de 2009, sendo que o exercício de 2010 foi de transição obrigatória. Em 2011, essa adoção tornou-se obrigatória para as companhias controladoras, controladas, de economia mista, estrangeiras, estatais e do setor público que tivessem ativos totais iguais ou superiores a US\$ 4.000 .000 (em 31 de dezembro de 2007). A partir 2012 as normas internacionais passaram a ser obrigatórias para as demais entidades.

No Paraguai, em 1989, o Conselho Diretivo do Colégio de Contadores emitiu uma resolução que estabeleceu a adoção das normas n. 1 a 5 emitidas pelo IASB, sendo que essas normas seriam aplicadas até que fossem elaboradas e aprovadas novas normas próprias. Já o Conselho Nacional de Valores estabeleceu que as IFRS teriam vigência a partir de 2008, com aplicação obrigatória para todas as sociedades emissoras de títulos e valores mobiliários de oferta pública.

No Peru, desde 1997, por meio da Lei das Sociedades, estabeleceu-se a 
obrigatoriedade das demonstrações financeiras serem preparadas e apresentadas em conformidade com as normas legais e os princípios de contabilidade geralmente aceitos, de acordo com as normas internacionais de contabilidade. O Conselho Normativo de Contabilidade, mediante a resolução específica, estabeleceu como obrigatória a aplicação das normas internacionais de contabilidade a partir de 2011.

No Uruguai, a convergência aos padrões internacionais de contabilidade iniciou na década de 1990. Já em 2004, o governo uruguaio aprovou a aplicação de todas as normas emitidas pelo IASB, e em 2007 orientou pela adoção integral das normas internacionais de informação financeira do IASB.

Na Venezuela, a emissão de normas contábeis está a cargo da Federação de Contadores Públicos da República Boliviana da Venezuela, a qual definiu que as normas internacionais de contabilidade deveriam ser adotadas, a partir de 2008, pelas grandes entidades. A partir do exercício econômico de 2011, a obrigatoriedade também passa a ser exigida para as demais entidades.

Em cada um dos países que compõem o Mercosul e a Comunidade Andina, há um organismo responsável pela emissão e interpretação das normas contábeis. Contudo, isso não significa que esses organismos emitam normas específicas de abragência interna. Em vários casos, como por exemplo, Paraguai, Uruguai, Venezuela e Equador, são adotadas as normas internacionais de contabilidade do IASB, sem adaptação ou emissão de uma norma correspondente no país.

Com relação ao nível de convergência às normas internacionais de contabilidade nos países que compõem os dois blocos, constatam-se distinções. Na Colômbia, há recomendação expressa para adoção das normas internacionais de contabilidade do IASB, e em outros países, como Brasil, Paraguai, Uruguai, Venezuela e Equador, a convergência às IFRS também está efetivada, pois organismos internos que emitem normas contábeis seguem as normas do IASB ao produzir as normas locais. Por sua vez, Argentina, Bolívia, Colômbia, Peru e Chile ainda não estavam convergidos às normas internacionais de contabilidade no ano de 2010.

Dessa forma, o processo de convergência às normas internacionais de contabilidade do IASB no Mercosul e na Comunidade Andina ainda está em curso. Pelo cronograma estabelecido, no ano de 2014 deverá haver completa convergência normativa com o IASB nos dois blocos econômicos que se constituem como objeto deste estudo.

\subsection{Tratamento Contábil dos Estoques no Mercosul e na Comunidade Andina}

Nos países do Mercosul, a convergência normativa no tratamento contábil dos estoques é quase integral, sendo exceção a Argentina que está com planos de convergência à IAS 2 desde 2011. Desse modo, apenas esse país possui normas locais vigentes relacionadas ao tratamento contábil dos estoques, conforme o Quadro 1. Nesse caso, a mensuração desse ativo é baseada no custo de reposição e a política de evidenciação envolve especialmente a divulgação de informações que se relacionem à política contábil e método de custeio adotado, valor dos estoques e sua classificação.

Da mesma forma, ocorrem tratamentos contábeis específicos na Comunidade Andina. É o caso da Bolívia e da Colômbia, onde os estoques são mensurados pelo valor de aquisição/produção e pelo valor histórico, respectivamente. Já o disclosure, em ambos, envolve a política e o método de custo adotado, valor dos estoques e sua classificação, além 
da provisão para perdas e obsolescência. Ressalta-se que na Bolívia o processo de convergência estava programado para o ano de 2011 e, na Colômbia, existiam planos de adoção das normas internacionais de contabilidade em 2012, mas ainda não há uma data definida para a implementação concreta.

Quadro 1 - Tratamento contábil dos estoques nos países do Mercosul e da Comunidade Andina

\begin{tabular}{|c|c|c|c|}
\hline Estoques & Definição & Mens uração & Evidenciação \\
\hline \multicolumn{4}{|c|}{ MERCOSUL } \\
\hline Argentina & $\begin{array}{l}\text { Bens destinados à venda no } \\
\text { curso normal da atividade da } \\
\text { empresa }\end{array}$ & Custo de Reposição & $\begin{array}{l}\text { Política contábil adotada e métodos de custo; } \\
\text { Valor dos estoques e sua classificação. }\end{array}$ \\
\hline Brasil & $\begin{array}{l}\text { CPC } 16(\mathrm{R} 1) \text { Estoques: } \\
\text { corresponde a IAS } 2\end{array}$ & CPC $16-$ Estoques & CPC 16 (R1) Estoques: corresponde a IAS 2 \\
\hline Paraguai & $\begin{array}{l}\text { NIF } 2 \text { - Inventarios: } \\
\text { correspondente a IAS } 2\end{array}$ & NIF 2 - Inventarios & NIF 2-Inventarios: correspondente a IAS 2 \\
\hline Uruguai & $\begin{array}{l}\text { NIC } 2 \text { - Inventarios: } \\
\text { correspondente a IAS } 2\end{array}$ & NIC 2 - Inventarios & NIC 2 - Inventarios: corres pondente a IAS 2 \\
\hline Venezuela & $\begin{array}{l}\text { NIC } 2 \text { - Inventarios: } \\
\text { correspondente a IAS } 2\end{array}$ & NIC 2 - Inventarios & NIC 2 - Inventarios: correspondente a IAS 2 \\
\hline \multicolumn{4}{|c|}{ COMUNIDADE ANDINA } \\
\hline Bolívia & $\begin{array}{l}\text { Compreende os produtos } \\
\text { adquiridos para a exploração } \\
\text { comercial e/ou industrial }\end{array}$ & $\begin{array}{l}\text { Custo de aquisição } \\
\text { (produção), } \\
\text { atualizado pela UFV }\end{array}$ & $\begin{array}{l}\text { Política contábil e métodos de custo; } \\
\text { Valor dos estoques e sua classificação; } \\
\text { Provisões perdas e obsolescência. }\end{array}$ \\
\hline Chile & $\begin{array}{l}\text { NIFCH } 2 \text { - Existências: } \\
\text { corresponde a IAS } 2\end{array}$ & $\begin{array}{l}\text { NIFCH } \quad 2 \quad- \\
\text { Existências. }\end{array}$ & NIFCH 2 - Existências: corresponde a IAS 2 \\
\hline Colômbia & $\begin{array}{l}\text { São bens corpóreos para a } \\
\text { venda no curso normal dos } \\
\text { negócios, bem como aqueles } \\
\text { que estão em produção, } \\
\text { utilizados ou consumidos na } \\
\text { produção de outros bens que } \\
\text { serão vendidos }\end{array}$ & $\begin{array}{lr}\text { Valor } & \text { histórico, } \\
\text { ajustado } & \text { pela } \\
\text { inflação } & \end{array}$ & $\begin{array}{l}\text { Política contábil e métodos de custo; } \\
\text { Taxas de conversão das mudanças contábeis; } \\
\text { Valor e sua classificação; } \\
\text { Provisão para perdas. }\end{array}$ \\
\hline Equador & $\begin{array}{l}\text { NIC } 2 \text { - Inventarios: } \\
\text { corresponde a IAS } 2\end{array}$ & NIC 2 - Inventarios & NIC 2 - Inventarios: corresponde a IAS 2 \\
\hline Peru & $\begin{array}{l}\text { NIC } 2 \text { - Inventarios: } \\
\text { corresponde a IAS } 2\end{array}$ & NIC 2 - Inventarios & NIC 2 - Inventarios: corresponde a IAS 2 \\
\hline
\end{tabular}

Fonte: Elaborado pelos autores.

Nos demais países, as normas que regulam o tratamento contábil dos estoques estão parametrizadas pela IAS 2 emitida pelo IASB, conforme apresentado no Quadro 1. São reconhecidos como estoques, nesses casos, aqueles ativos mantidos para a venda no curso normal dos negócios, que estejam em processo de produção ou aqueles materiais e suprimentos que serão consumidos ou transformados no processo de produção ou na prestação de serviços (IAS 2, 2005).

Conforme as normas contábeis internacionalmente aceitas, os estoques devem ser mensurados pelo valor de custo ou pelo valor realizável líquido, devendo ser adotado aquele 
método que resultar no menor valor do bem. O custo final do estoque envolve o somatório de todos os custos de aquisição, transformação e os demais incorridos para colocá-los em local e condição atual. (CPC 16, 2009). Já o valor realizável líquido é o valor que a entidade prevê realizar com a venda desses bens durante o curso dos negócios, sendo que, nesse caso, os estoques não são escriturados com valores superiores àqueles pelos quais se espera que sejam realizados (SILVA; SILVA; DENBERG, 2011).

As políticas de evidenciação, conforme a IAS 2 (2005), exigem que as entidades divulguem a política contábil e os métodos de custos adotados, o valor dos estoques e sua classificação, os estoques registrados a valores justos, os estoques baixados como despesas por venda, consumo ou a valor realizável líquido, as reversões, os motivos de baixa e os estoques mantidos em garantia.

\subsection{Estudos Empíricos precedentes relacionados à harmonização contábil e relativos ao tratamento contábil de estoques e as normas internacionais de contabilidade}

Inicialmente cabe destacar alguns estudos dedicados ao tema da convergência das normas contábeis aos padrões harmonizados internacionalmente.

Silva, Madeira e Assis (2004) abordaram as inúmeras diferenças estruturais e culturais entre as normas internacionais e as divergências no processo de regulamentação adotadas em vários países e órgãos emissores de padrões contábeis. Apontaram para uma divisão do mundo em dois campos distintos, ou seja, os seguidores do IASB e os do FASB, embora já houvesse uma tendência à harmonização entre esses organismos. Também apontavam para a existência de resistências regionais, apoiadas nos sistemas jurídicos de cada país, tradições, regionalismos e nacionalismos exacerbados, como fatores que retardavam o processo de harmonização contábil.

Andrade e Martins (2009) analisaram criticamente as normativas sobre as contabilizações das PPPs, tendo por base a IFRIC 12. Observaram que a mensuração dos riscos é matéria polêmica de difícil mensuração tanto econômica quanto contábil, em que a norma (IFRIC 12) foi omissa, sendo um dos seus pontos negativos. Referem ainda que as normas contábeis não podem esquecer o caráter preditivo da Contabilidade, em que a essência tem que prevalecer sobre a forma.

Ao realizar análise de periódicos internacionais para verificar os temas das pesquisas em educação contábil face à convergência e globalização dos relatórios financeiros, Cella, Rodrigues e Niyama (2011) observaram que são três os mais frequentes: educação continuada da classe contábil, harmonização e convergência internacional da Contabilidade, e assuntos para pesquisa em contabilidade. Concluem que o foco da atenção dos educadores em Contabilidade, para fazer frente às mudanças impostas pela convergência da contabilidade internacional e pela globalização dos relatórios financeiros, deve estar na permanente educação continuada.

Os procedimentos contábeis adotados para a mensuração dos estoques foram abordados, especificamente no âmbito dos dois blocos econômicos objeto desta pesquisa, de forma mais genérica. Lisboa (2000), por exemplo, buscou verificar se os procedimentos contábeis dos países-membros do Mercosul estavam harmonizados e identificou que não havia uniformidade de práticas adotadas.

O estudo de Amenábar (2001) analisou o processo de harmonização contábil na Argentina, no Brasil, no Peru e na Venezuela por meio da identificação das principais 
semelhanças e diferenças nas normas contábeis utilizadas. Quanto às políticas de avaliação de estoques, observou que ocorria uma regra comum nesses países: valor de custo ou valor de mercado, de ambos, menor. Dessa forma, nenhum elemento poderia ser registrado por um valor maior do que aquele que realmente vale economicamente para a empresa.

Demais pesquisas relativas a metodologias de mensuração de estoques foram desenvolvidas nos últimos anos e estão relacionadas com a aplicação nas normas internacionais de contabilidade. Murphy (2005) verificou em um grupo de empresas se a adoção de normas internacionais de contabilidade fez com que elas alterassem os métodos contábeis relativos aos estoques. Constatou que as normas internacionais do IASB influenciaram diretamente na escolha de novas metodologias para mensuração desses elementos, embora o nível de harmonia das informações tenha diminuído visto a falta de divulgação de informações conforme os padrões.

Reis e Stocken (2007) analisaram as consequências da mensuração desses ativos pelo custo histórico e pelo valor justo, em um mercado competitivo. Observaram que com a utilização do valor justo, em evidência na IAS 2, os relatórios financeiros revelam de maneira completa a real situação dos estoques, e isso proporciona a geração de maiores lucros esperados, diminuição de incertezas, além de gerar maior bem-estar social para a empresa.

Krishnan e Lin (2012) analisaram as principais consequências da adoção da IAS 2 por empresas dos Estados Unidos, que até o momento utilizam princípios contábeis próprios. Entre os dois padrões existem pontos em comum no que se refere aos requisitos de avaliação de estoques, mas eles diferem na medição inicial, mensuração subsequente, e nos requisitos de divulgação e impacto fiscal. A adoção da IAS geraria uma pressão sobre as empresas, principalmente no que se refere a alterações em sistemas de informação, controles internos e planejamento fiscal.

O estudo desenvolvido por Yereli, Kayali e Demirlioglu (2012) fez uma comparação entre os procedimentos adotados na Turquia e aqueles descritos na IAS 2, com relação ao método de custeio dos estoques. Constataram que os dois métodos resultam em grandes diferenças nos registros contábeis, o que pode ocasionar divergências fiscais, por isso, referendam a necessidade de harmonizar as práticas.

A partir dos estudos referidos, observa-se que ainda ocorrem disparidades no tratamento dos estoques. Constata-se que ainda há oportunidades de pesquisas sobre os procedimentos contábeis relativos a esses elementos e sua harmonização em âmbito mundial. Devido à importância que a harmonização contábil remete, esse fator proporciona relevância às pesquisas que contribuam para a melhoria nos procedimentos técnicos contábeis relacionados à esses elementos patrimoniais.

\section{Considerações Metodológicas}

A presente pesquisa pode ser caracterizada como aplicada e descritiva. Aplicada, pois busca contribuir com fins práticos para a geração do conhecimento da temática abordada, com a finalidade de analisar e identificar, a partir dos relatórios contábeis, as assimetrias ou simetrias existentes na avaliação e na evidenciação de elementos patrimoniais (estoques), em empresas do setor industrial dos países integrantes do Mercosul e da Comunidade Andina. É descritiva, pois objetiva descrever e analisar as práticas contábeis observadas, procurando avaliar o estágio de harmonização e convergência na mensuração e evidenciação dos estoques 
nesses países.

Com relação aos procedimentos de coleta dos dados, aplicou-se uma pesquisa documental. Foram utilizadas informações contidas nas publicações oficiais das companhias definidas na amostra referentes ao ano de 2010 e disponíveis nas páginas eletrônicas dos organismos que regulam o mercado de capitais de cada país. Dessa forma, os dados relativos ao tratamento contábil dos estoques foram coletados a partir dos Balanços Patrimoniais e das notas explicativas publicadas pelas empresas nas páginas eletrônicas já referidas.

A população é constituída pelas companhias abertas que negociam suas ações nos mercados de capitais dos países integrantes dos blocos econômicos do Mercosul e da Comunidade Andina. Num total de 2.128 empresas registradas no site das CNV e CVM, foram identificadas 295 empresas do ramo industrial. A partir da quantidade de empresas industriais desses países, optou-se por selecionar três empresas em cada país, sendo que o critério de escolha foi o maior faturamento anual combinado com maior valor de ativos. A amostra final ficou constituída por 30 empresas, representando, assim, 10\% da população.

Com relação à forma como se buscou dar resposta à problemática abordada no estudo, as análises envolvem técnicas de natureza qualitativa, sem a utilização de técnicas estatísticas. Os dados coletados na pesquisa foram analisados por meio da técnica de análise de conteúdo, em três fases: pré-análise, exploração do material e interpretação (BARDIN, 2009). Inicialmente, foram identificadas e discutidas as normas que regulam o tratamento contábil dos estoques nos diferentes países, com vistas a estabelecer um padrão para análise.

Na sequência, a partir dos dados obtidos nas demonstrações contábeis, procedeu-se à descrição e análise dos métodos de mensuração e formas de evidenciação inerentes aos estoques. Nessa fase, os dados coletados foram organizados em quadros elaborados a partir das práticas contábeis observadas nas empresas em cada um dos blocos econômicos. Isso possibilitou uma melhor exploração do material para sua interpretação e análise.

\section{Resultados do Estudo}

\subsection{Avaliação e Evidenciação dos Estoques nos países do Mercosul}

Com relação aos critérios de mensuração adotados pelas empresas do Mercosul, o Quadro 2 apresenta os principais procedimentos adotados.

Quadro 2 - Mensuração dos estoques em empresas do Mercosul

\begin{tabular}{|c|c|c|c|c|c|}
\hline $\begin{array}{c}\text { Mens uração dos } \\
\text { Estoques } \\
\end{array}$ & Argentina & Brasil & Paraguai & Uruguai & Venezuela \\
\hline \multirow[t]{2}{*}{ Critério } & $\begin{array}{l}\text { Custo de } \\
\text { produção }\end{array}$ & $\begin{array}{c}\text { Custo de } \\
\text { aquisição ou } \\
\text { construção }\end{array}$ & \multirow{2}{*}{$\begin{array}{l}\text { Custo de } \\
\text { aquisição }\end{array}$} & $\begin{array}{c}\text { Custo de } \\
\text { aquisição ou } \\
\text { construção }\end{array}$ & \multirow{2}{*}{$\begin{array}{l}\text { Custo de } \\
\text { aquisição }\end{array}$} \\
\hline & $\begin{array}{l}\text { Custo de } \\
\text { reposição }\end{array}$ & $\begin{array}{c}\text { Valor realizável } \\
\text { líquido } \\
\end{array}$ & & $\begin{array}{c}\text { Valor realizável } \\
\text { líquido } \\
\end{array}$ & \\
\hline Método & Não informado & $\begin{array}{l}\text { Custo médio } \\
\text { ponderado }\end{array}$ & $\begin{array}{c}\text { Preço médio } \\
\text { ponderado }\end{array}$ & $\begin{array}{l}\text { Custo médio } \\
\text { ponderado }\end{array}$ & Custo médio \\
\hline
\end{tabular}

Fonte: Dados da pesquisa.

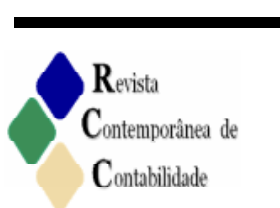

ISSN 2175-8069, UFSC, Florianópolis, v. 10, n. 21, p. 51-70, set./dez. 2013 
No que se refere ao método utilizado para a avaliação do valor dos estoques, observase que o custo médio ponderado foi adotado em três países, sejam Brasil, Paraguai e Uruguai. Nas empresas da Venezuela, houve menção apenas ao custo médio, enquanto que nas empresas argentinas não foi informado o critério utilizado. Com relação ao método de valoração dos estoques, constatou-se aderência ao que está expresso na norma internacional do IASB (IAS 2), em quatro países do Mercosul, sendo que apenas nas empresas argentinas não foi possível identificar o método utilizado. As constatações deste estudo são coerentes com os achados de Amenábar (2001), que obsevou na Argentina, no Brasil, no Peru e na Venezuela que avaliação de estoques possuía uma regra comum, ou seja, valor de custo ou valor de mercado, de ambos, menor.

Em referência à divulgação de informações relativas aos estoques nas empresas do Mercosul, o Quadro 3 explicita as principais políticas adotadas e identificadas no balanço patrimonial e nas notas explicativas.

Quadro 3 - Evidenciação relativa aos estoques em empresas do Mercosul

\begin{tabular}{|c|c|c|c|c|c|}
\hline $\begin{array}{l}\text { Evidenciação } \\
\text { dos Estoques }\end{array}$ & Argentina & Brasil & Paraguai & Uruguai & Venezuela \\
\hline $\begin{array}{c}\text { Balanço } \\
\text { Patrimonial }\end{array}$ & $\begin{array}{c}\text { Conta: Inventários } \\
\text { Valor: total do } \\
\text { grupo }\end{array}$ & $\begin{array}{c}\text { Conta: Estoques } \\
\text { Valor: total do } \\
\text { grupo }\end{array}$ & $\begin{array}{c}\text { Conta: Estoques } \\
\text { Valor: total do } \\
\text { grupo }\end{array}$ & $\begin{array}{c}\text { Conta: Estoques } \\
\text { Valor: total do } \\
\text { grupo }\end{array}$ & $\begin{array}{l}\text { Conta: Estoques } \\
\text { Valor: total do } \\
\text { grupo }\end{array}$ \\
\hline \multirow{3}{*}{$\begin{array}{c}\text { Notas } \\
\text { Explicativas }\end{array}$} & $\begin{array}{l}\text { Políticas contábeis } \\
\text { e método de custeio }\end{array}$ & $\begin{array}{c}\text { Políticas contábeis } \\
\text { e método de } \\
\text { custeio }\end{array}$ & $\begin{array}{l}\text { Políticas contábeis } \\
\text { e método de custeio }\end{array}$ & $\begin{array}{l}\text { Políticas contábeis } \\
\text { e método de custeio }\end{array}$ & $\begin{array}{c}\text { Políticas contábeis } \\
\text { e método de } \\
\text { custeio }\end{array}$ \\
\hline & $\begin{array}{c}\text { Detalhamento das } \\
\text { contas de estoques }\end{array}$ & $\begin{array}{c}\text { Detalhamento das } \\
\text { contas de estoques }\end{array}$ & \begin{tabular}{|c|} 
Detalhamento das \\
contas de estoques
\end{tabular} & $\begin{array}{c}\text { Detalhamento das } \\
\text { contas de estoques }\end{array}$ & $\begin{array}{l}\text { Detalhamento das } \\
\text { contas de estoques }\end{array}$ \\
\hline & $\begin{array}{l}\text { Quadro do custo } \\
\text { das mercadorias } \\
\text { vendidas (CMV): } \\
\text { saldo inicial, } \\
\text { compras, saldo } \\
\text { final e o CMV }\end{array}$ & $\begin{array}{l}\text { Provisões para } \\
\text { perdas e } \\
\text { obsolescência; } \\
\text { Revisão do valor } \\
\text { líquido de } \\
\text { realização }\end{array}$ & $\begin{array}{l}\text { Provisões para } \\
\text { perdas e } \\
\text { obsolescência. }\end{array}$ & $\begin{array}{l}\text { Provisões para } \\
\text { perdas e } \\
\text { obsolescência. }\end{array}$ & $\begin{array}{l}\text { Provisões para } \\
\text { perdas e } \\
\text { obsolescência; } \\
\text { Revisão do valor } \\
\text { líquido de } \\
\text { realização }\end{array}$ \\
\hline
\end{tabular}

Fonte: Dados da pesquisa.

Nas empresas dos países do Mercosul, os estoques são apresentados no balanço patrimonial em conta individual, com o valor líquido global agrupado a essa conta. As diferenças identificadas na apresentação dos estoques no balanço patrimonial estão relacionadas à nomenclatura, visto que na Argentina, no Paraguai e na Venezuela as empresas estudadas adotam a conta inventários (inventarios), enquanto que no Brasil as empresas utilizam a conta denominada estoques e, por sua vez, as empresas uruguaias utilizam a designação bens de comercialização (bienes de cambio). Entende-se essas diferenças de nomenclatura como normais em decorrência das distintas formas de linguagem dos países.

Com relação às informações reveladas nas notas explicativas, observou-se que nos países do Mercosul todas as empresas pesquisadas apresentam uma nota comum, a qual informa sobre as políticas contábeis adotadas, bem como o método de custeio empregado para a determinação do valor dos estoques. Também se observa uniformidade com relação à nota explicativa que detalha, item por item, a composição do valor global líquido dos estoques apresentado no balanço patrimonial. 
Em quatro países (Brasil, Paraguai, Uruguai e Venezuela), as empresas apresentaram nota explicativa informando sobre a constituição de provisão para obsolescência e perdas nos estoques. Em dois países (Brasil e Venezuela), há em nota explicativa da realização de revisão ao valor líquido realizável dos estoques, o que condiz com determinação da IAS 2. Política de evidenciação distinta foi observada nas empresas argentinas, pois essas não apresentam provisões ou ajustes no valor dos estoques, informando apenas em quadro específico a composição do custo das mercadorias vendidas, ou seja, saldo inicial dos estoques, compras do exercício, saldo final dos estoques e o respectivo custo das mercadorias vendidas.

Pelo observado, depreende-se significativa convergência na evidenciação dos estoques nas empresas do Mercosul, sendo a principal divergência observada em empresas da Argentina, pela não constituição ou referência a provisões ou ajustes nos valores dos estoques. Esses achados guardam coerência com a observação de Lisboa (2000), que também identificou que não havia uniformidade completa de práticas adotadas em relação ao tema.

\subsection{Avaliação e Evidenciação dos Estoques nos países da Comunidade Andina}

Observou-se que, na Comunidade Andina, o critério de mensuração de estoques adotado pelas empresas analisadas é predominantemente o do custo histórico de aquisição, produção ou construção, conforme demonstra o Quadro 4. Como exceção, destacam-se as empresas colombianas, as quais não foram analisadas devido à ausência de notas explicativas nas demonstrações contábeis publicadas na página eletrônica da Superintendência Financeira da Colômbia, não sendo possível, dessa forma, identificar os critérios em uso para valoração dos estoques.

Quadro 4 - Mensuração dos estoques em empresas da Comunidade Andina

\begin{tabular}{|c|c|c|c|c|c|}
\hline $\begin{array}{c}\text { Mens uração dos } \\
\text { Es toques }\end{array}$ & Bolívia & Chile & Colômbia & Equador & Peru \\
\hline \multirow[t]{2}{*}{ Critérios } & \multirow{2}{*}{$\begin{array}{l}\text { Custo de } \\
\text { aquisição ou } \\
\text { produção } \\
\text { atualizado pela } \\
\text { UFV }\end{array}$} & $\begin{array}{c}\text { Custo de } \\
\text { aquisição ou } \\
\text { construção }\end{array}$ & \multirow{2}{*}{$\begin{array}{c}\text { Sem dados para } \\
\text { análise }\end{array}$} & \multirow{2}{*}{$\begin{array}{l}\text { Custo de } \\
\text { aquisição ou } \\
\text { construção }\end{array}$} & $\begin{array}{l}\text { Custo de } \\
\text { aquisição }\end{array}$ \\
\hline & & $\begin{array}{c}\text { Valor realizável } \\
\text { líquido }\end{array}$ & & & $\begin{array}{c}\text { Valor realizável } \\
\text { líquido }\end{array}$ \\
\hline Método & $\begin{array}{c}\text { Custo médio } \\
\text { ponderado } \\
\text { atualizado }\end{array}$ & $\begin{array}{l}\text { Preço médio } \\
\text { ponderado }\end{array}$ & $\begin{array}{c}\text { Sem dados para } \\
\text { análise }\end{array}$ & $\begin{array}{l}\text { Custo médio / } \\
\text { fabricação }\end{array}$ & $\begin{array}{l}\text { Custo médio } \\
\text { ponderado }\end{array}$ \\
\hline
\end{tabular}

Fonte: Dados da pesquisa.

$\mathrm{Na}$ Bolívia, o custo dos estoques é corrigido pela unidade de desenvolvimento habitacional (UFV - unidad de fomento a la vivienda) no encerramento do exercício. No Chile e no Peru, constatou-se que além do critério de custo, as empresas utilizam o valor realizável líquido como sistemática para proceder aos ajustes de valor nos seus estoques.

Também se observa em empresas chilenas, peruanas e bolivianas, a utilização do método do preço médio ponderado para a valoração dos estoques, contudo, nas empresas bolivianas, esse método é também atualizado pela UFV no final do exercício. Nas empresas equatorianas ocorre menção ao método do custo médio ou custo de fabricação, sem referência

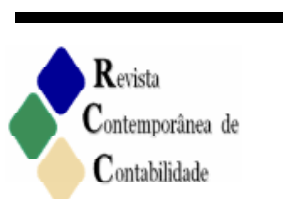

ISSN 2175-8069, UFSC, Florianópolis, v. 10, n. 21, p. 51-70, set./dez. 2013 
à ponderação ou não. Por sua vez, nas empresas da Colômbia não se identificou o método utilizado pela ausência de notas explicativas.

A partir dessas informações, constata-se aderência completa ao que está expresso na IAS 2, especificamente sobre método de valoração de estoques, em apenas dois países (Chile e Peru), sendo que nos demais (Bolívia e Equador) a aderência é parcial, por não haver referência ao critério de valor realizável líquido. Como já referido, nas empresas colombianas não foi possível avaliar o nível de convergência pela não publicação de notas explicativas às demonstrações contábeis.

Em relação ao disclosure de informações relativas aos estoques nas empresas da Comunidade Andina, observou-se que, em entidades de quatro países (Bolívia, Chile, Equador e Peru), os estoques são apresentados no balanço patrimonial em conta individual, com o valor líquido total já agrupado, conforme é apresentado no Quadro 5. Já nas empresas colombianas, os valores são apresentados por item e pelo total do grupo.

Assim como nos países do Mercosul, nesse caso também ocorrem as diferenças na apresentação dos estoques no balanço patrimonial decorrentes da denominação das contas. Em quatro países (Bolívia, Chile, Colômbia e Equador), as empresas analisadas adotam a conta inventários (inventarios) e as empresas peruanas utilizam a conta existências (existencias). Tais diferenças, pressupõe-se que sejam decorrentes das características de cada país.

Quadro 5 - Evidenciação inerente aos estoques em empresas da Comunidade Andina

\begin{tabular}{|c|c|c|c|c|c|}
\hline $\begin{array}{l}\text { Evidenciação } \\
\text { dos Estoques }\end{array}$ & Bolívia & Chile & Colômbia & Equador & Peru \\
\hline \multirow{2}{*}{$\begin{array}{c}\text { Balanço } \\
\text { Patrimonial }\end{array}$} & $\begin{array}{c}\text { Conta: } \\
\text { Inventários }\end{array}$ & $\begin{array}{c}\text { Conta: } \\
\text { Inventários }\end{array}$ & Conta: Inventários & $\begin{array}{c}\text { Conta: } \\
\text { Inventários }\end{array}$ & $\begin{array}{c}\text { Conta: } \\
\text { Existências }\end{array}$ \\
\hline & $\begin{array}{l}\text { Valor: total do } \\
\text { grupo }\end{array}$ & $\begin{array}{l}\text { Valor: total do } \\
\text { grupo }\end{array}$ & $\begin{array}{l}\text { Valor: por item e } \\
\text { total do grupo }\end{array}$ & $\begin{array}{l}\text { Valor: total do } \\
\text { grupo }\end{array}$ & $\begin{array}{l}\text { Valor: total do } \\
\text { grupo }\end{array}$ \\
\hline \multirow{3}{*}{$\begin{array}{c}\text { Notas } \\
\text { Explicativas }\end{array}$} & $\begin{array}{c}\text { Políticas } \\
\text { contábeis e } \\
\text { método de } \\
\text { custeio }\end{array}$ & $\begin{array}{c}\text { Políticas } \\
\text { contábeis e } \\
\text { método de } \\
\text { custeio }\end{array}$ & $\begin{array}{c}\text { Ausência de notas } \\
\text { explicativas }\end{array}$ & Não informado & $\begin{array}{l}\text { Políticas } \\
\text { contábeis e } \\
\text { método de } \\
\text { custeio }\end{array}$ \\
\hline & $\begin{array}{c}\text { Detalhamento } \\
\text { das contas de } \\
\text { estoques } \\
\end{array}$ & $\begin{array}{c}\text { Detalhamento das } \\
\text { contas de } \\
\text { estoques } \\
\end{array}$ & $\begin{array}{c}\text { Ausência de notas } \\
\text { explicativas }\end{array}$ & $\begin{array}{c}\text { Detalhamento } \\
\text { das contas de } \\
\text { estoques } \\
\end{array}$ & $\begin{array}{c}\text { Detalhamento } \\
\text { das contas de } \\
\text { estoques } \\
\end{array}$ \\
\hline & $\begin{array}{c}\text { Provisões para } \\
\text { perdas e } \\
\text { obsolescência }\end{array}$ & $\begin{array}{c}\text { Provisões para } \\
\text { perdas e } \\
\text { obsolescência }\end{array}$ & $\begin{array}{c}\text { Ausência de notas } \\
\text { explicativas }\end{array}$ & $\begin{array}{c}\text { Provisões para } \\
\text { perdas e } \\
\text { obsolescência }\end{array}$ & $\begin{array}{c}\text { Provisões para } \\
\text { perdas e } \\
\text { obsolescência }\end{array}$ \\
\hline
\end{tabular}

Fonte: Dados da pesquisa.

De acordo com as informações reveladas nas notas explicativas, verifica-se que nas empresas da Comunidade Andina, especificamente na Bolívia, no Chile e no Peru, ocorre a evidenciação das políticas contábeis e do método de custeio empregado na determinação do valor dos estoques. Nas empresas equatorianas tal evidenciação não consta em notas explicativas. Nas empresas colombianas esse item não foi identificado devido à ausência de divulgação das notas explicativas sobre as demonstrações contábeis.

Adicionalmente, observou-se na Bolívia, no Chile, no Equador e no Peru, uma nota explicativa uniforme, que detalha item a item, a composição do valor global líquido dos estoques demonstrado no balanço patrimonial. Da mesma forma, as empresas analisadas 
desses países apresentaram item em nota explicativa que informa sobre a constituição de provisão para perdas e obsolescência no grupo dos estoques.

Dessa forma, identifica-se significativa convergência das práticas adotadas na evidenciação dos estoques das empresas da Comunidade Andina aos padrões internacionais. A principal divergência encontrada foi em empresas colombianas, pela falta de publicação de notas explicativas.

\subsection{Análise da Convergência à Norma De Estoques Do IASB No Mercosul E Na Comunidade Andina Em 2010}

Para possibilitar uma análise comparativa entre convergência normativa e convergência nas práticas contábeis relativas a estoques nos dois blocos econômicos em estudo, apresenta-se a Figura 1.

Figura 1 - Convergência das práticas estudadas com a norma internacional de contabilidade em 2010

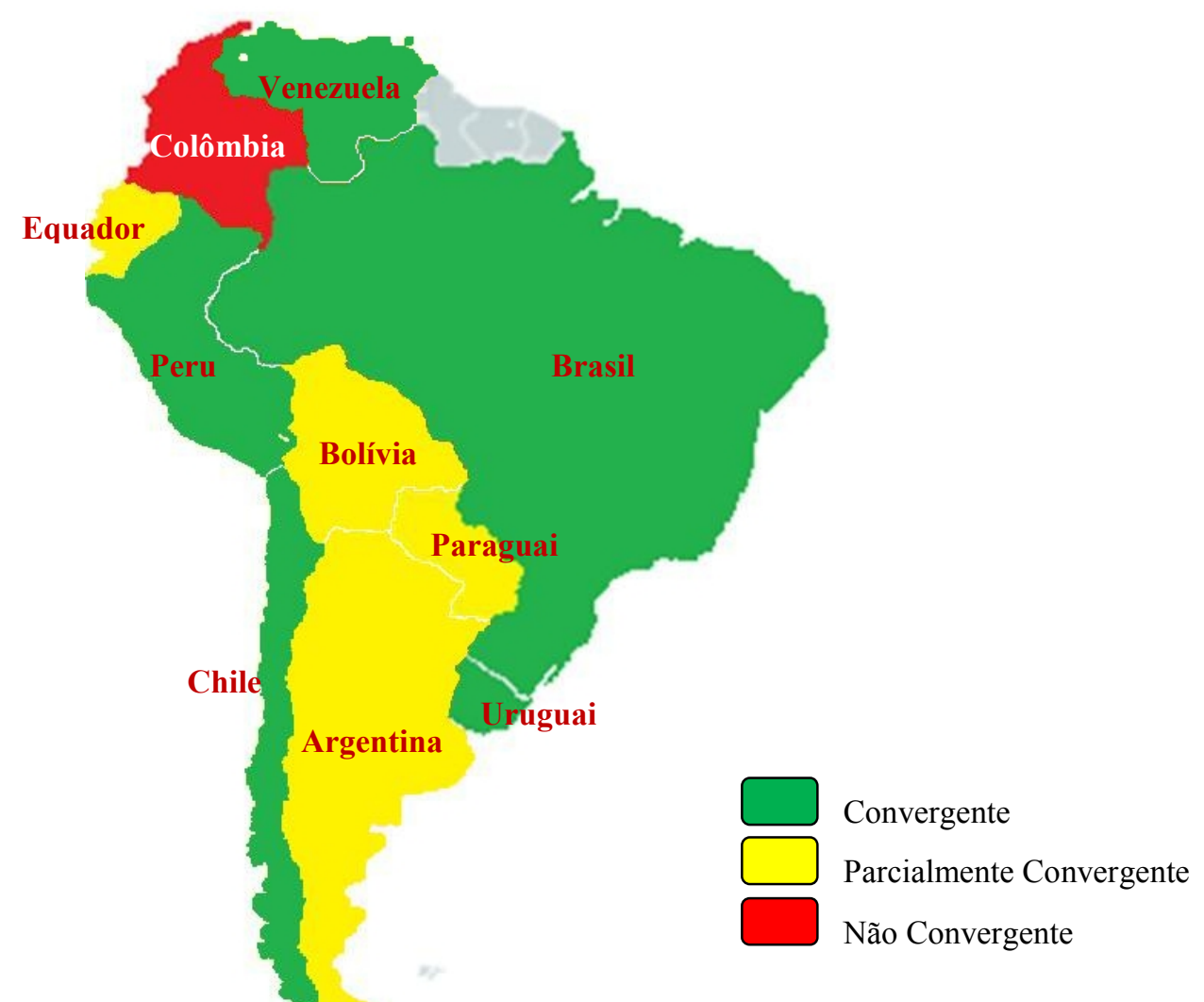

Fonte: Dados da pesquisa.

Em referência à convergência aos padrões internacionais, constatam-se aspectos relevantes nos países do Mercosul. No Brasil, no Uruguai e na Venezuela, há convergência normativa ao padrão IASB e também é possível identificar convergência nas práticas contábeis observadas nas empresas pesquisadas. No Paraguai, apesar da convergência 
normativa ao padrão IASB, observa-se convergência parcial nas práticas contábeis, e na Argentina, apesar de não haver em 2010 convergência normativa ao padrão IASB, observa-se convergência parcial nas práticas contábeis quanto à mensuração e evidenciação dos estoques.

Da mesma forma, ocorrem situações peculiares na Comunidade Andina com relação à convergência. No Chile, há convergência normativa ao padrão IASB e também é possível identificar convergência nas práticas contábeis observadas nas empresas pesquisadas. No Peru e na Bolívia, apesar de não haver, em 2010, convergência normativa ao padrão IASB, observa-se a convergência nas práticas contábeis nas empresas pesquisadas quanto à mensuração e evidenciação dos estoques. No Equador, apesar da convergência normativa ao padrão da IAS 2, observa-se convergência parcial nas práticas contábeis nas empresas pesquisadas. Na Colômbia, não há, em 2010, convergência normativa ao padrão IASB, nem mesmo convergência nas práticas contábeis, quanto à mensuração e evidenciação dos estoques, nas empresas pesquisadas.

As constatações advindas do estudo revelam que o processo de convergência à norma internacional de contabilidade (IAS 2), nos países do Mercosul e da Comunidade Andina, deve estar concluído até o final de 2014. Para que isso se confirme, o calendário previsto para a convergência, principalmente na Colômbia, deve ter sua conclusão efetivada nas datas estabelecidas. Percebe-se que a convergência das normas contábeis aos padrões do IASB é algo iminente nos países desses blocos econômicos, o que pode facilitar o processo de harmonização contábil nesta região.

Contudo, a realidade observada em práticas contábeis de empresas industriais nos países desses dois blocos econômicos revela que a convergência e a harmonização estão bem mais distantes. Observa-se no estudo e nos aspectos sintetizados na Figura 1, que o fato de adotar a norma contábil convergente não garantiu sua observância em alguns países. Em países dos dois blocos econômicos, com normas convergentes ao padrão IASB, identifica-se tanto práticas convergentes como parcialmente convergentes. Mesmo em países como a Argentina, no qual as normas IASB ainda não estão implementadas, as práticas contábeis revelam-se parcialmente convergentes a esse padrão internacional.

\section{Conclusões}

Por meio deste estudo, buscou-se analisar o nível de convergência de práticas contábeis relacionadas aos estoques em relação à norma do IASB. A pesquisa envolveu empresas industriais do Mercosul e da Comunidade Andina e analisou aspectos sobre a mensuração e evidenciação de estoques nos países desses blocos econômicos.

A partir dos dados coletados, constatou-se que na maioria dos países do Mercosul, as práticas contábeis estudadas, relativas à mensuração e evidenciação dos estoques, estão convergentes com o que requer a IAS 2. Nas empresas brasileiras e uruguaias, as práticas contábeis observadas estão totalmente convergentes com o padrão internacional. No caso das empresas da Venezuela, apesar de terem sido observadas algumas práticas parcialmente convergentes, pode-se inferir também convergência ao padrão IASB. Nos demais países do Mercosul (Argentina e Paraguai), observou-se convergência parcial na mensuração e evidenciação dos estoques, decorrente de uma divulgação não integral de informações requeridas nas normas internacionais. 
Mesmo que as práticas contábeis, no que se refere à mensuração e evidenciação dos estoques, tenha revelado um nível convergente ou parcialmente convergente nas empresas estudadas do Mercosul, concluiu-se que ainda falta uma maior homogeneidade nesses procedimentos. Esses resultados não são muito distintos daqueles já observados anteriormente, visto que Lisboa (2000) também já havia identificado que não havia uniformidade de práticas adotadas na mensuração dos estoques no Mercosul. Embora esta situação tenha avançado, no atual estudo ainda não se observou completa harmonização, principalmente no que tange a evidenciação inerente ao tratamento contábil dos estoques.

Os resultados desta pesquisa também convergem com os achados de Amenábar (2001), visto que se mantêm em empresas no Mercosul, a avaliação dos estoques a Custo ou Valor Líquido Realizável (ou alternativamente valor de mercado). No estudo referido, realizado na Argentina, no Brasil, no Peru e na Venezuela, observou-se que a avaliação de estoques seguia uma regra comum: valor de custo ou valor de mercado, de ambos, menor, o que não deixa de ser muito similar ao que se pôde observar na amostra ora analisada.

Na Comunidade Andina, dois países (Chile e Peru) apresentaram as práticas contábeis de estoques convergentes com o que preconiza a norma do IASB. Já na Bolívia e em Equador, as práticas adotadas podem ser consideradas parcialmente convergentes com a IAS 2, pois não há uma divulgação integral de informações requeridas nas normas emitidas pelo IASB. A Colômbia é o único país onde as práticas não são convergentes, pois as informações em notas explicativas não estão disponíveis aos usuários. Embora as empresas possam ter publicado seus balanços patrimoniais e demonstrações de resultados, a falta de informações em notas explicativas revela uma grande limitação, remetendo a não convergência com os padrões internacionais.

Desse modo, pode-se afirmar que na Comunidade Andina ocorrem práticas contábeis relacionadas aos estoques que tendem a uma convergência ao padrão IASB. Mas da mesma forma que no Mercosul, ainda há uma distância muito significativa para se atingir uma harmonização total nos procedimentos.

A partir do que se observou em empresas da Comunidade Andina, cabe retomar os achados de Murphy (2005), o qual constatou que as normas internacionais do IASB influenciaram diretamente na escolha de novas metodologias para mensuração dos estoques, mas em contrapartida o nível de harmonia das informações registrou uma diminuição pela falta de divulgação de informações conforme os padrões. Essa questão da incompletude ou absoluta falta de divulgação, como se observou na Colômbia, foi o principal aspecto que evidenciou que o tratamento contábil dos estoques em empresas da Comunidade Andina ainda não se mostra convergente aos padrões internacionais.

Concluiu-se, a partir do estudo, que o simples fato de quem em alguns países já se adote a IAS 2, não garantiu sua observância por completo. Em alguns países de ambos os blocos econômicos que aderiram à convergência ao padrão IASB, observaram-se tanto práticas convergentes como parcialmente convergentes. Dessa forma, pode-se afirmar que a prática contábil é influenciada pelas características próprias de cada país e que a harmonização não significa a adoção de um padrão único e comum, mas sim, harmonizado. Além disso, a adoção de um conjunto de normas comuns, como são as normas internacionais de Contabilidade do IASB, pode não garantir, ao menos de imediato, a adoção de práticas contábeis convergentes e harmonizadas.

O que se pôde concluir está coerente com o que já referiam Silva, Madeira e Assis (2004), visto que os mesmos apontavam para a existência de resistências regionais, apoiadas 
nos sistemas jurídicos de cada país, tradições, regionalismos e nacionalismos exacerbados, como fatores que retardavam o processo de harmonização contábil.

Adicionalmente, entende-se como relevantes as contribuições de Cella, Rodrigues e Niyama (2011) que entendem que o foco da atenção dos educadores em Contabilidade, para fazer frente às mudanças impostas pela convergência da contabilidade internacional e pela globalização dos relatórios financeiros, deve estar na permanente educação continuada.

Conclui-se que a educação contínua e as pesquisas aplicadas relacionadas ao tema possam contribuir para que as resistências regionais, tradições, regionalismos e nacionalismos exacerbados, apontados como fatores que retardam o processo de harmonização contábil, possam ser superados e que se possa alcançar, ao menos em médio prazo, a convergência contábil em níveis mais aceitáveis.

Para finalizar, cabe referir que diante desse cenário de integração econômica regional, é importante estimular pesquisas com o objetivo de verificar o processo de harmonização nos países do Mercosul e da Comunidade Andina, pois esse fator contribui para a geração de informações integradas e harmonizadas, facilitando o acesso a informações homogêneas pelos usuários. Dessa forma, a partir dos dados obtidos nesta pesquisa e da significância do tema abordado, recomenda-se ampliar esta abordagem com a análise dos demais elementos patrimoniais, de possíveis divergências estruturais e de conteúdo das demonstrações contábeis de divulgação obrigatória e dos impactos financeiros na aplicação das normas internacionais do IASB nesses blocos econômicos.

\section{Referências}

AMENÁBAR, A. M. H. Harmonização contábil em cinco países da América do Sul. 2001. 415f. Dissertação (Mestrado em Controladoria e Contabilidade) - Programa de Pós-Graduação em Controladoria e Contabilidade. Universidade de São Paulo, São Paulo, SP, 2001.

ANDRADE, Maria Elisabeth M. Carvalho; MARTINS, Vinícius Aversari. Análise dos Normativos de Contabilidade Internacional sobre Contabilização de Contratos de Parcerias Público-Privadas. RCC - Revista Contemporânea de Contabilidade. UFSC, Florianópolis, ano 06, v.1, n. 11, p. 83-107, Jan./Jun., 2009.

BARDIN, L. Análise de conteúdo. 5. ed. Lisboa: Edições 70, 2009.

BASSO, M. Integração econômica e institucionalização: as experiências do Mercosul e da União Européia. Disponível em: <http://www.cjf.gov.br/revista/numero4/artigo9.html $>$. Acesso em: 20 nov. 2010.

CELLA, Gilson; RODRIGUES, Jomar Miranda; NIYAMA, Jorge Katsumi. Contabilidade Internacional - análise dos periódicos internacionais sobre pesquisas em educação contábil face à convergência e globalização. RCC - Revista Contemporânea de Contabilidade. UFSC, Florianópolis, v. 8, n. 15, p. 177-198, jan./jun., 2011. 
COMITÊ DE PRONUNCIAMENTOS CONTÁBEIS. Pronunciamento Técnico CPC 16: estoques. Brasília, DF, 08 de maio de 2009. Disponível em:

$<$ http://www.cpc.org.br/pdf/CPC_16_R1.pdf >. Acesso em: 3 abr. 2012.

FLORÊNCIO, S. A. L.; ARAÚJO, E. H. F. MERCOSUL hoje. São Paulo: Alfa-Omega, 1998.

INTERNATIONAL ACCOUNTING STANDARDS BOARD. International Accounting Standard 2. Disponível em: $<$ http://eifrs.iasb.org/eifrs/bnstandards/en/ias2.pdf $>$. Acesso em: 3 abr. 2012.

IUDÍCIBUS, S. D.; MARTINS, E.; GELBCKE, E. R.; SANTOS, A. D. Manual de contabilidade societária: aplicável a todas as sociedades. São Paulo: Atlas, 2010.

KRISHNAN, S.; LIN, P. Inventory valuation under IFRS and GAAP. Strategic Finance, p. $51-58,2012$.

KRONBAUER, C. A. Contabilización y divulgación de información relativa al impuesto sobre benefícios: una comparación entre lãs normas españolas y brasileñas. Suficiência investigadora (Trabajo de Investigación). Sevilla, ES, 2006.

KUNZLER, J. P. Mercosul e o comércio exterior. 2. ed. São Paulo: Aduaneiras, 2001.

LEONE, G. S. G; LEONE; R. J. G. Curso de contabilidade de custos. São Paulo: Atlas, 2010 .

LISBOA, N. P. Harmonização de normas e práticas contábeis no Mercosul. 2000. $121 \mathrm{f}$. Tese (Doutorado em Controladoria e Contabilidade) - Programa de Pós-Graduação em Controladoria e Contabilidade. Universidade de São Paulo, São Paulo, SP, 2000.

MACIEL, R. R. Como implantar as normas internacionais de contabilidade: IFRS. Curitiba: Juruá, 2009.

MERCOSUR, Secretaria del. Normativa 2012. Disponível em:

<http://www.mercosur.int/innovaportal/v/4392/1/secretaria/2012>. Acesso em: 8 ago. 2012.

MURPHY, A. B. The influence of international accounting standards on companies choice of accounting methods. Journal of Accounting and Finance. v. 13, n. 2, p. 101-114, 2005.

NIYAMA, J. K. Contabilidade internacional. São Paulo: Atlas, 2010.

POHLMANN, M. C. Harmonização contábil no Mercosul: a profissão e o processo de emissão de normas: uma contribuição. Caderno de estudos. São Paulo, n. 12, set. 1995.

REIS, R. R.; STOCKEN, P. C. Strategic consequences of historical cost and fair value measurements. Contemporary Accounting Research. v. 24, n. 2, p. 557-584, 2007. 
SÁNCHEZ, I. M. G. Contabilidad financiera, general o externa: evolución y perspectivas del proceso de armonización internacional. In: . Síntesis de la ciência contable. [S.1.], 2010. Disponível em: <http://www.eumed.net/libros/2010b/686/contabilidad>. Acesso em: 14 jan. 2011.

SCARIOT, F. Estudo multicaso de conformidade de avaliação mensuração e divulgação de estoques em relação ao CPC 16 das Normas Brasileiras de Contabilidade. Electronic Accounting and Management. Curitiba, v. 3, n. 3, p. 1-15, 2011.

SILVA, Cátia B. Amaral da; MADEIRA, Geová José; ASSIS, José L. Ferreira de. Harmonização de Normas contábeis: um estudo sobre as divergências entre normas contábeis internacionais e seus reflexos na contabilidade brasileira. RCC - Revista Contemporânea de Contabilidade. UFSC, Florianópolis, ano 01, v. 1, n. 1, p. 115-139, jan./jun., 2004.

SILVA, A. F. S.; SILVA, E. P.; DENBERG, M. W. Mensuração do fair value de ativos tangíveis: estoque e ativo imobilizado. Revista Pensar Contábil. Rio de Janeiro, v. 13, n. 51, p. 48-55, 2011.

SOSA, A. J. Origens, evolução e perspectivas do MERCOSUL. Buenos Aires, 1999. Disponível em: <http://www.amersur.org.ar/Integ/OEPMercosur.htm>. Acesso em: 15 jan. 2011.

SOSA, A. J. EI MERCOSUR político: orígenes, evolución y perspectivas. Buenos Aires, março, 2008. Disponível em: <http://www.amersur.org.ar/Integ/OEPMercosur.html >. Acesso em: 15 jan. 2011.

SOSA, A. J.; FERRETTI, M. M. América do Sul: um breve relato sobre seu processo de integração. Buenos Aires, abril, 2007. Disponível em:

$<$ http://www.amersur.org.ar/Integ/OEPMercosur.html>. Acesso em: 15 jan. 2011.

SOUZA, M. A.; DIEHL, C. A. Gestão de custos: uma abordagem integrada entre Contabilidade, Engenharia e Administração. São Paulo: Atlas, 2009.

YERELI, A. N.; KAYALI, N.; DEMIRLIOGLU, L. Maliyetlerin tespitinde normal maliyet yöntemi: tms 2 stoklar standardi ilê vergi mevzuati'nin karsilastirilmasi ve uymlastirilmasi. Mali Cozum Dergisi, p. 21-41, 2012. 
